\title{
The Paramedian Scalp Reduction with Posterior Z-Plasty
}

\author{
A Technique to Minimize the "Slot" Defect \\ BRUCE R. NELSON, MD • DOWLING B. STOUGH, MD \\ MONTGOMERY GILLARD • D. BLUFORD STOUGH, MD \\ TIMOTHY M. JOHNSON, MD
}

BACKGROUND: One consistent and undesired sequela resulting from scalp reductions has been the "slot" or "trough" defect, referring to the scar following the final reduction. Attempts to correct this have not been entirely satisfactory. OBJECTIVE: To present an approach to minimize the "slot" defect that consists of staged modified paramedian scalp reductions combined with a large posterior Z-plasty during the final reduction.

METHODS: A paramedian crescent-shaped ellipse was marked onto the patient's scalp parallel and adjacent to the existing fringe hair. Subsequent reductions were performed in a similar manner approximately 2 months apart. The final reduction consisted of mobilization and transposition of the large flaps used in the posterior Z-plasty.

RESULTs: Patients who underwent the staged modified paramedian reductions combined with a posterior Z-plasty had significant minimization and adequate camouflage of the undesirable "slot."

CONCLUSION: Combining a large posterior Z-plasty with a paramedian reduction minimizes the slot defect. J Dermatol Surg Oncol 1992;18:996-998.
$\mathbf{T}$ he addition of scalp reductions has become an integral part of hair transplantation surgery for alopecia. Since the advent of scalp reduction surgery in the mid 1970s many modifications and refinements have been made in an attempt to maximize the effectiveness and final aesthetic result. ${ }^{1-22}$ While modern scalp reduction surgery is predictable and successful, one consistent undesired sequela known as the "slot," or "trough" frequently results. "This refers to the scar that remains following the final reduction. The hair on both sides of the scar is oriented in a lateral direction, ie, away from the scar. This often results in a significantly visible scar that is difficult to camouflage. Attempts to correct this scar have not been entirely satisfactory. We present our current approach to this problem which consists of staged modified paramedian scalp reductions combined with a posterior Z-plasty during the final reduction surgery.

Most of the refinements added to scalp reduction surgery have been directed at preventing and correcting the "slot" or "trough" defect. Some have tried multiple Z-plasties (Stough DB, personal communication) or transplanted grafts into the scar. Frechet ${ }^{15}$ recently advocated combining scalp reductions

From the Department of Dermatology, Otorhinolaryngology, and Surgery (Division of Plastic Surgery) (BRN, MG, TMD), University of Michigan Medical Center, Ann Arbor, Michigan; Stough Dermatology and Dermatologic Plastic Surgery Clinic, Hot Springs, and the Department of Dermatology (DBS, DBS III), University of Arkansas for Medical Sciences, Little Rock, Arkansas.

Address all correspondence to: Bruce $R$ Nelson, MD, University of Michigan Medical Center, Department of Dermatology, 1910-0314 Taubman Center, Ann Arbor, MI 48109. with a transposition flap and possibly an advancement flap into the posterior aspect of the reduction. Aside from the techniques of Frechet, ${ }^{7,15}$ the results of these techniques have generally not been entirely satisfactory to correct the posterior slot scar. Our approach to eliminating this posterior slot scar consists of staged modified paramedian scalp reductions combined with a large Z-plasty at the posterior aspect of the incision line during the final reduction procedure.

\section{Technique}

Prior to the actual procedure, a paramedian crescent-shaped ellipse is marked onto the patient's scalp with a sterile marking pen (Figure 1). The ellipse is then placed parallel and adjacent to the existing fringe hair. The ellipse is usually placed on the same side that the patient parts his hair from. The anterior aspect extends to a point several centimeters posterior to the designed anterior hairline. The posterior aspect extends across the midline and below the hair whorl on the contralateral side. The area of excision is then prepped and draped in a sterile manner. A pericephalic block ${ }^{23}$ is then administered. The patient is placed on a Prōn Pillō (Robbins Instruments, Chatham, NJ), and a paramedian scalp reduction is performed utilizing the Shaw Scalpel $^{24}$ (Hemostatix Corporation, Redwood City, CA), Iconclast $^{25}$ (Robbins Instruments, Chatham, NJ), and a lighted retractor (Van Sickle Instruments, Bedford, TX) with standard surgical techniques.

Subsequent reductions are performed in a similar manner approximately 2 months apart. The final reduction (Figure 1) is designed to allow for adequate excision of the remaining area of alopecia anteriorly over the vertex but no attempt is made to excise tissue posteriorly other than the previous scar. This will allow for loose posterior hair-bearing scalp after wide under- 

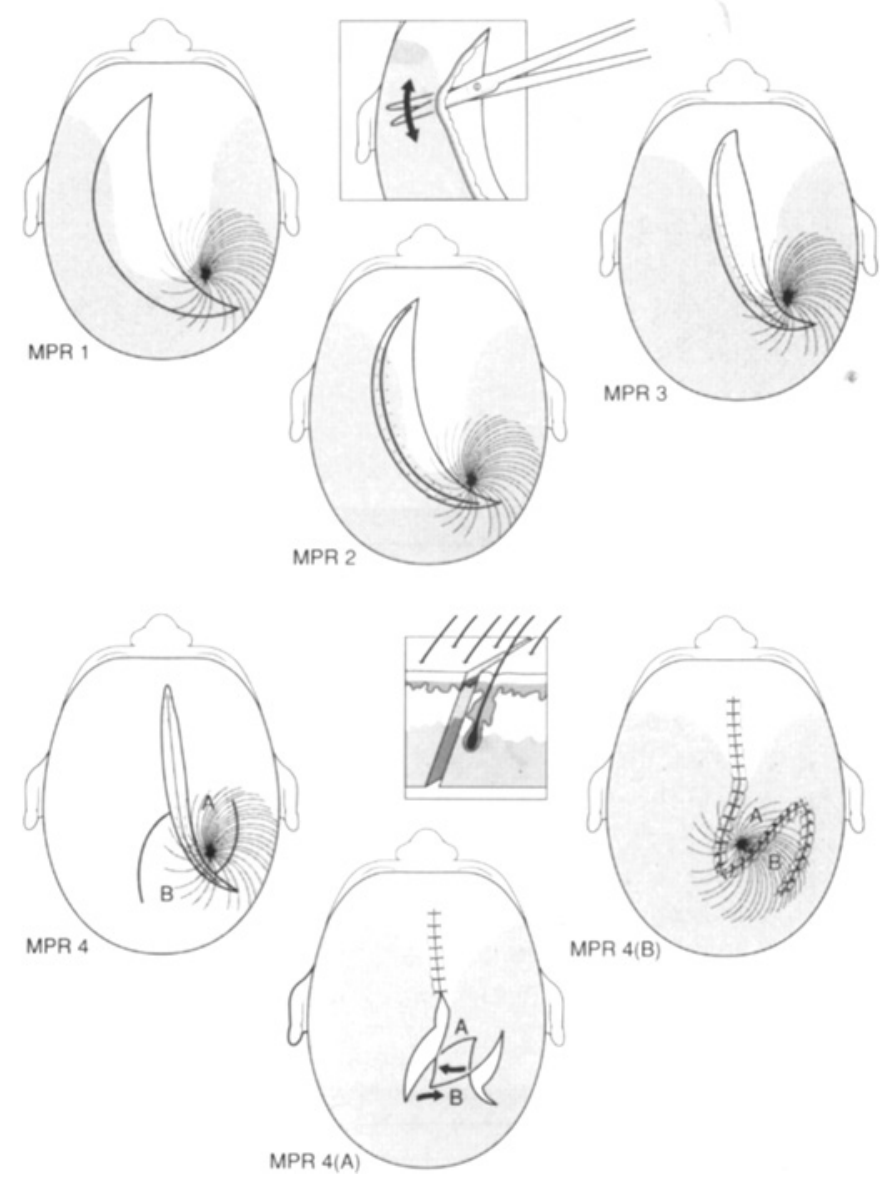

Figure 1. Top: Male pattern reductions (MPRs) \#1-\#3 are shown. Note extension of incision beneath hair whorl. MPR \#4 with combined posterior Z-plasty. Note direction of hair whorl. mining, which is essential for the mobilization and transposition of the large flaps to be used in the Z-plasty.

\section{Comment}

Many refinements of scalp reduction surgery have been made since 1975. The list is quite long and includes the paramedian reduction, ${ }^{10,17}$ mercedes reduction, ${ }^{20}(\mathrm{~S}, \mathrm{~J}$, and $\mathrm{C}$ type lateral patterns $\left.^{22,26}\right)$, U-pattern, minireductions, ${ }^{21,26}$ M-plasties, Frechet flap, ${ }^{17}$ Brandy flap, ${ }^{12}$ Unger's modified major scalp reduction, ${ }^{16,26}$ Juri flap, ${ }^{18}$ curvilinear reduction, ${ }^{19}$ triple rhomboid flap, ${ }^{21}$ and combinations of the above. No single procedure can be ideal for all patients; each patient must be considered individually. All of the above procedures have pros and cons that are well beyond the scope of this article. The Brandy flap ${ }^{12,26} \mathrm{can}$ be used to excise a tremendous amount of alopecic scalp as well as eliminate or markedly reduce the "slot" deformity. It is a very extensive procedure and as such requires a considerable amount of experience to perform properly. Tissue expansion also allows for more alopecic scalp to be excised. It is a two staged procedure requiring weekly injections into the expander. Unfortunately many patients are unwilling to undergo this procedure because of cosmetic concerns. It can be quite disfiguring during the expansion phase.

The paramedian reduction with certain modifications has distinct advantages which should be stressed. It is a relatively simple procedure requiring 15 to 20 minutes of actual surgery time. Alt $^{10,17}$ has demonstrated that the paramedian reduction results in less distortion of the frontal hairline, which permits more extensive undermining - providing for coronal advancement of the hair-bearing a donor site and allowing for a greater amount of camouflage of the scalp reduction scar during the immediate postoperative period. The paramedian crescenteric reduction, when performed in combination with a posterior Z-plasty, can result in a natural appearing result which minimizes the "slot" defect and maintains the hair whorl.

Figure 2. Left: MPR \#2. Note previous scar from MPR \#1. Right: Same patient 1 month following final MPR and Z-plasty.
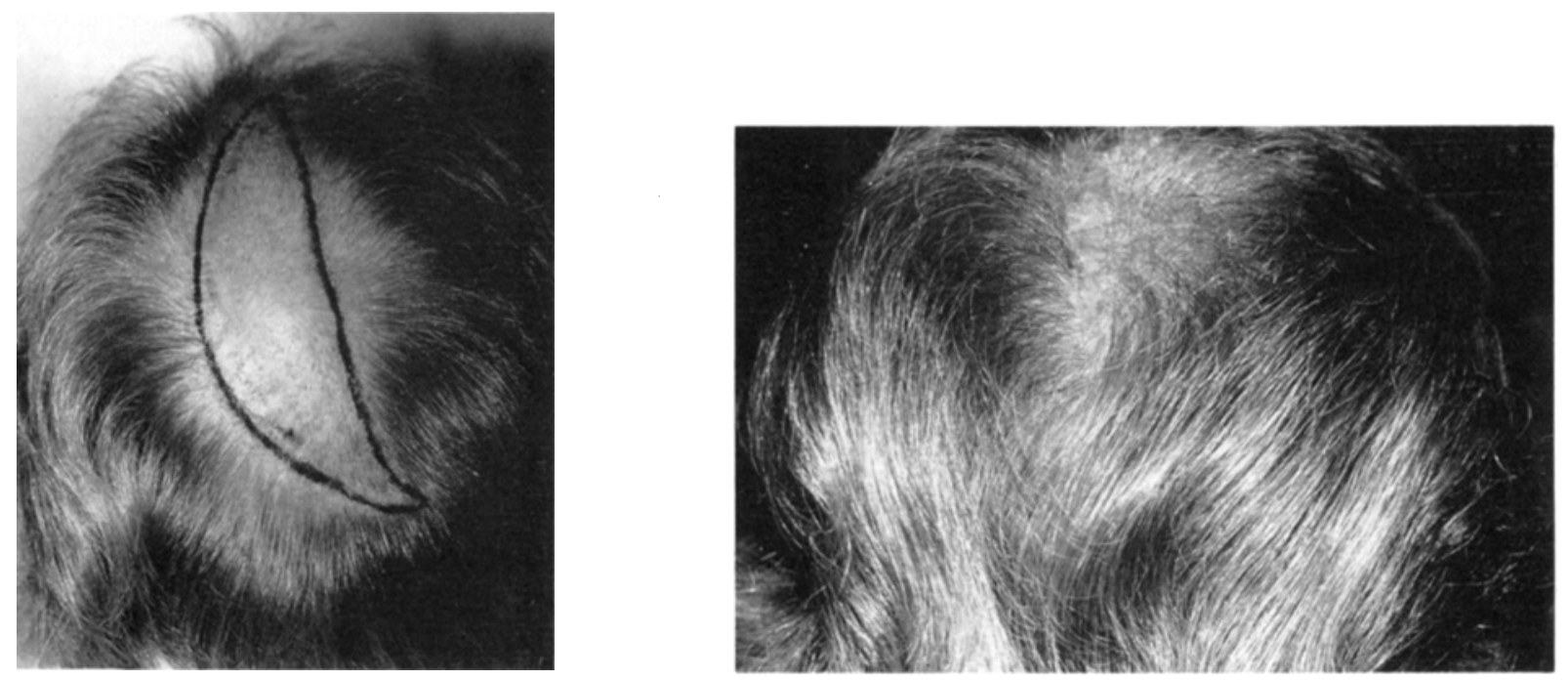
Success of this procedure depends on the several key points. First, the paramedian reduction is designed with the anterior incision placed on the patient's part side. This will allow for, as previously stated, coverage of the scar by combing of hair over the incision line. The paramedian incision line should extend across the mivdline into the marginal fringe hair below the hair whorl (Figures 1 and 2). Maximum mobilization of the limbs of the Z-plasty is usually performed during the final reduction. This is accomplished by limiting the amount of tissue excised at the posterior aspect of the incision. Only the scar or minimal tissue from the previous reduction is excised. In the process of performing the Z-plasty the direction of hair growth in the superior limb is usually converted from a clockwise orientation to more of a superior to inferior direction (Figure 1). It does however, maintain the clockwise whorl. The hair whorl, if there is one, is therefore maintained. This will often improve the cosmetic result by camouflaging the scars at the posterior pole of the excision. Furthermore, the use of the paramedian reduction with extension across the midline to a position under the swirl enables the patient to cover the posterior scar with the hair from above the incision (Figure 2). This design results in camouflage of the posterior scars. If desired, additional hair grafts can be transplanted into the residual scars after the final reduction and Z-plasty.

The advent of scalp reduction surgery has been a major asset to hair transplant surgeons. The one distinct weakness is the creation of the "slot," which is aesthetically displeasing. We believe that the combination of modified paramedian staged reductions with a final large Z-plasty at the posterior aspect of the incision line provides one efficient, simple, and practical way to minimize and help camouflage this undesirable "slot."

\section{References}

1. Norwood OT, Shiell R, Morison I. Complications of scalp reductions. J Dermatol Surg Oncol 1983;9:831-4.

2. Blanchard G, Blanchard B. La réduction de la tonsure ("détonsuration") concept nouveau dans le traitement chirurgical de la calvitie. l'Union Med du Can 1976;105:618-24.

3. Blanchard G, Blanchard B. Obliteration of alopecia by hair lifting: a new concept and techniques. J Natl Med Assoc 1977;69:639-41.

4. Sparkuhl K. Scalp reduction: serial excision of the scalp with flap advancement. Int Hair Transpl Symp [Lucerne], 1978.

5. Stough DB, Webster RC. Esthetics and refinements in hair transplantation. Int Hair Transpl Symp [Lucerne], 1978.

6. Bosley L, Hope C, Montroy RE, Staub PM. Reduction of male pattern baldness in multiple stages: a retrospective study. J Dermatol Surg Oncol 1980;6:498-508.
7. Frechet $P$. How to avoid the principal complication of scalp reduction in the management of extensive alopecia. J Dermatol Surg Oncol 1985;11:637-40.

8. Unger MG, Unger WP. Management of alopecia of the scalp by a combination of excision and transplantation. J Dermatol Surg Oncol 1978;4:670-2.

9. Bosley LL, Hope C, Montroy RE. MPR for surgical reduction of male-pattern baldness. Curr Ther Res 1978;25: 281-7.

10. Alt TH. Scalp reduction as an adjunct to hair transplantation: review of relevant literature and presentation of an improved technique. J Dermatol Surg Oncol 1980;6: 1011-8.

11. Schultz BC, Roenigk HH Jr. Scalp reduction for alopecia. J Dermatol Surg Oncol 1979;5:808-11.

12. Brandy DA. The bilateral occipitoparietal flap. J Dermatol Surg Oncol 1986;12:1062-6.

13. Stough DB, Cates JA, Dean AJ. Updating reduction and flap procedures for baldness. Ann Plast Surg 1982;8:287.

14. Norwood OT. Scalp reduction in the treatment of androgenic alopecia. Dermatol Clin 1987;5:531-44.

15. Frechet $P$. A new method for correction of the vertical scar observed following scalp reduction for extensive alopecia. J Dermatol Surg Oncol 1990;16:640-4.

16. Unger MG. The modified major scalp reduction. J Dermatol Surg Oncol 1988;14:80-4.

17. Alt TH. Advantages of the paramedian scalp reduction. J Dermatol Surg Oncol 1988;14:257-64.

18. Juri J. Use of parieto-occipital flaps in the surgical treatment of baldness. Plast Reconstr Surg 1975;55:456-60.

19. Hitzig GS, Sadick NS. A new technique for curvilinear scalp reduction. J Dermatol Surg Oncol 1989;15:1108-12.

20. Unger MG. The $Y$-shaped pattern of alopecia reduction and its variations. J Dermatol Surg Oncol 1984;10:980-6.

21. Stough DB, Stough DB. Triple rhomboid flap for crown alopecia correction. J Dermatol Surg Oncol 1990;16:543-8.

22. Unger MG. Scalp reductions. Facial Plast Surg 1985;2: 253-8.

23. Moore DC. Regional Block, 4th ed. Springfield, IL: Charles C Thomas, 1965.

24. Fee WE. Use of the Shaw scalpel in head and neck surgery. Otolaryngol Head Neck Surg 1981;89:515-9.

25. Webster RC, Pedroza F, Hall B, Hopping SB, Smith RC, Smith KF. The iconoclast as an aid in blunt dissection of flaps of the scalp and forehead. J Dermatol Surg Oncol 1982;8:793-5.

26. Unger WP, Nordström REA. Hair Transplantation, 2nd ed. New York: Marcel Dekker, 1988:102-8. 